Case Report

\title{
Dental patient with acromegaly: a case report
}

\author{
Roopashri R. Kashyap ${ }^{1)}$, Gogineni S. Babu ${ }^{2)}$ and Shishir R. Shetty ${ }^{2)}$ \\ ${ }^{1)}$ Department of Oral Medicine and Radiology, A. J. Institute of Dental Sciences, Mangalore, India \\ ${ }^{2)}$ Department of Oral Medicine and Radiology, A. B. Shetty Memorial Institute of Dental Sciences, \\ Mangalore, India
}

(Received 21 September 2010 and accepted 10 February 2011)

\begin{abstract}
Acromegaly is an acquired disorder related to excessive production of growth hormone after epiphyseal closure of bones. It is characterized by progressive somatic disfigurement (mainly involving the face and extremities) and systemic manifestations. The prevalence is estimated at 1:140,000-250,000. Although acromegaly rarely manifests in the orofacial regions, it must be considered in patients who develop malocclusion after adolescence. Here, we present a case of acromegaly with brief review of the literature. (J Oral Sci 53, 133-136, 2011)
\end{abstract}

Keywords: acromegaly; growth hormone; pituitary gland; macroglossia.

\section{Introduction}

Acromegaly is characterized by an acquired progressive somatic disfigurement, mainly affecting the face and extremities. It also involves many other organs and is associated with systemic manifestations. This term was proposed by Pierre Marie, a famous French neurologist, and was derived from the Greek words akros, meaning extremities, and megas, meaning big (1). Acromegaly is a rare disease with a prevalence of 40 to 70 cases per million people in the population and an annual incidence of 3 to 4 patients per million (2). The characteristic signs and symptoms of acromegaly arise from the effects of excess human growth hormone produced by a pituitary adenoma or from other concomitant endocrinological

Correspondence to Dr. Roopashri Rajesh Kashyap, Department of Oral Medicine and Radiology, A. J. Institute of Dental Sciences, Mangalore 575004, India

Tel: +91-09448910793

E-mail: roopashri.r.k@gmail.com involvement after the closure of epiphyseal plates.

\section{Case Report}

A 45-year-old female patient reported with the complaint of mobility of a lower left back tooth of 2 weeks duration. It was associated with pain of insidious onset, mild and intermittent nature, aggravated on chewing and relieved on taking analgesics. Past medical history revealed that patient had acromegaly due to a growth hormone secreting pituitary adenoma and had undergone transsphenoidal surgery 7 years previously. She had the history of headache associated with vomiting, blurring of vision in the left eye, galactorrhoea, change in voice, excessive growth of body hair, polymenorrhoea, heat intolerance and sweating before surgery. She had to undergo re-exploration transnasal transsphenoidal surgery and excision of tumour as the growth hormone level was more than $40 \mathrm{ng} / \mathrm{ml}$. The patient was under a maintenance dose of prednisolone (Tab. Wysolone $5 \mathrm{mg}$ OD). Dental history revealed uneventful extraction of mandibular right and left first molars 6 months previously.

General physical examination revealed a well built stature and coarse voice. Vital signs and cranial nerve assessment were normal. The extremities (hands and feet) were broadened, and the fingers were widened, thickened and stubby (Fig. 1). Head and neck examination revealed enlarged nose, thickened lips, and mild prognathism of the mandible. Intra oral examination revealed moderately enlarged tongue (Fig. 2) and generalized gingival recession. Increased spacing was noted between the teeth. Upper right molars, upper left first and second molars, lower right and left first molars were missing. Teeth were buccally inclined (Fig. 3). Lower anteriors and premolars on both sides, lower left molars and upper right canine teeth exhibited grade 3 mobility. The case was provisionally 


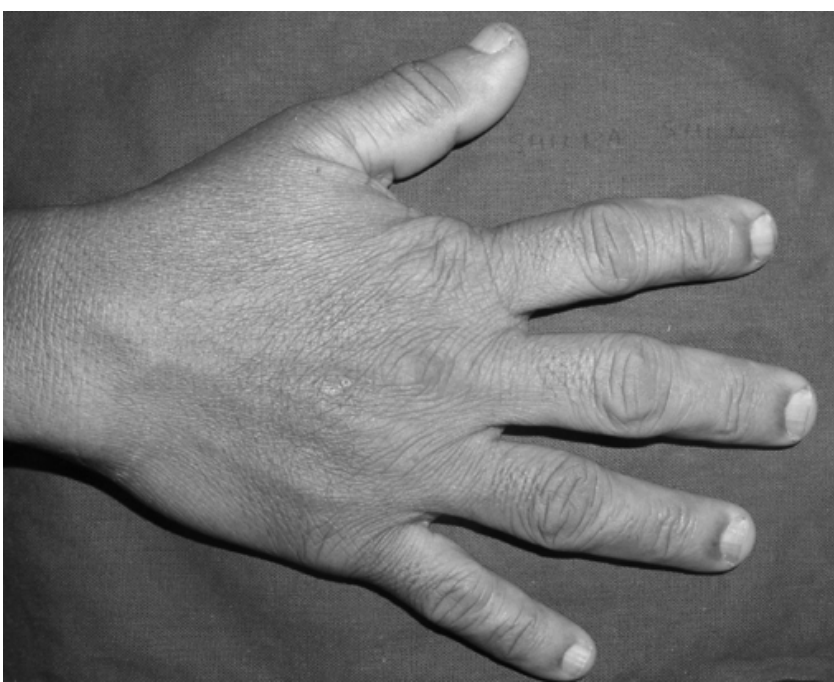

Fig. 1 Broad hand with short stubby fingers.

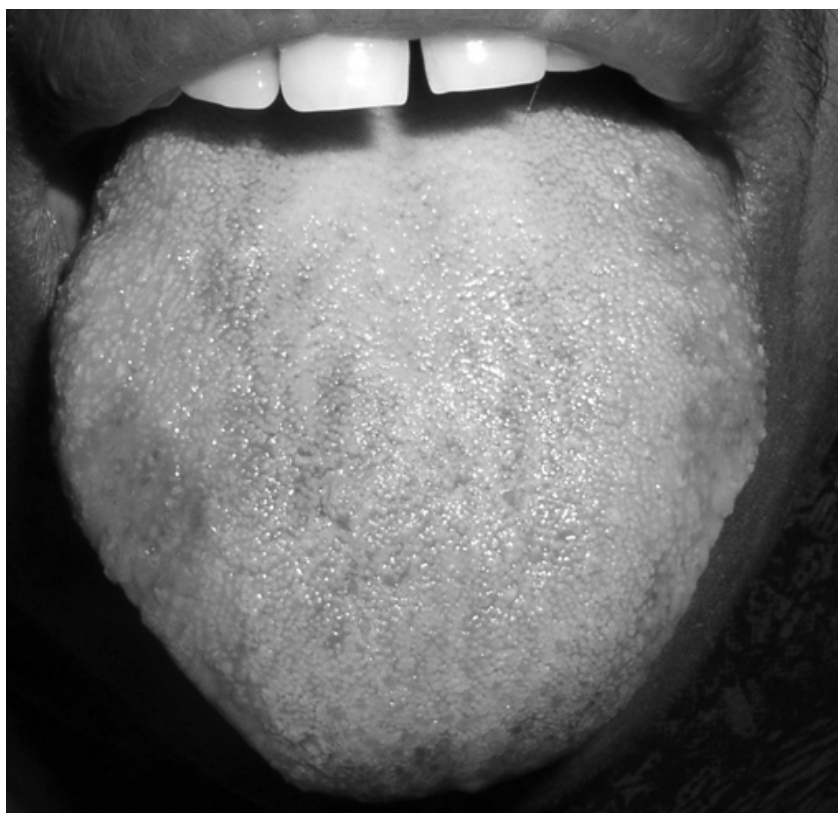

Fig. 2 Macroglossia

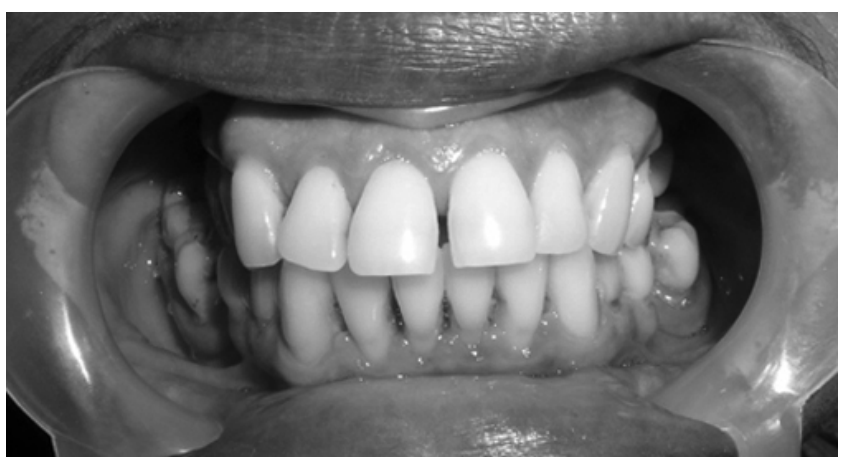

Fig. 3 Buccally tilted lower molars diagnosed as chronic generalized periodontitis in a case of acromegaly. Intra oral periapical radiograph in relation to the left lower molar showed normal density of enamel, dentin and pulpal radiolucency. Roots appeared to be bulkier suggestive of hypercementosis (Fig. 4). Lamina dura was continuous. Interdental horizontal alveolar bone loss was seen extending $5 \mathrm{~mm}$ below the cementoenamel junction involving the furcation area. Panoramic radiograph revealed elongated right and left condyles and coronoid process. Inferior cortical border appeared to be normal. Roots of all molars exhibited hypercementosis. Lateral cephalogram showed enlarged sella turcica, enlarged frontal sinus, steep mandibular angle and class III profile with prognathic mandible (Fig. 5). Hand wrist radiograph revealed osteophyte formation and mineralization of ligamentous insertion (Fig. 6) Biochemical analysis of growth hormone by ELISA revealed a higher value of $10.9 \mathrm{ng} / \mathrm{ml}$ (normal range 0-6 $\mathrm{ng} / \mathrm{ml}$ ) and fasting blood glucose level was $128 \mathrm{mg} / \mathrm{dl}$. The patient was advised to have the lower left first molar extracted after medical evaluation, followed by periodontal therapy and prosthetic rehabilitation.

\section{Discussion}

Acromegaly is a multisystem disorder resulting from chronic exposure to supraphysiological levels of growth hormone and insulin-like growth factor-1 (IGF-1) and is associated with significant morbidity and increased mortality. In more than $95 \%$ of patients, the aetiology is pituitary somatotrophinoma. The resultant clinical syndrome is characterized by excessive skeletal growth, soft tissue enlargement, and shortened life expectancy (3). Affected individuals may present with symptoms related to mass effect of local tumour growth or excess of growth hormone and IGF-1. The clinical manifestations may range from subtle physical changes to obvious disfiguring features. Due to the insidious nature of the disease, the early changes may go unnoticed by patients. The more evident changes are those related to soft tissue enlargement and skeletal growth (4).

Acromegaly can cause a variety of symptoms, such as malodorous sweating (especially at night), headache, acroparesthesia and joint pain. A progressive deepening of the voice is also observed as seen in our case. Skin thickening is due to glycosaminoglycan deposition and increased collagen production by connective tissue. The extremities (hands and feet) are broadened, the fingers are widened, thickened and stubby, and spade-like and the soft tissue is thickened. Changes in the extremities are not only due to soft tissue hypertrophy or excess growth of bone and cartilage but also due to bone deformation. In 


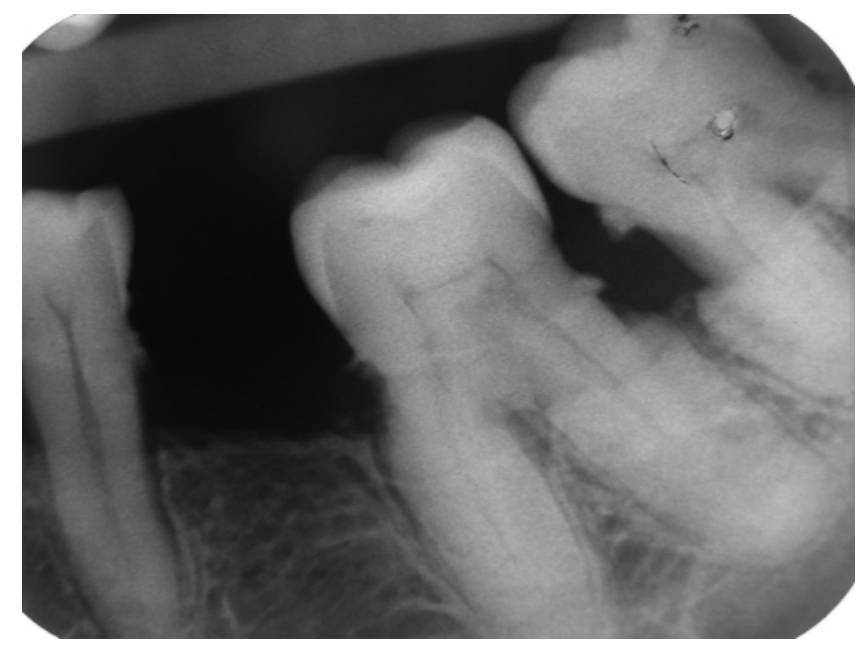

Fig. 4 Intraoral periapical radiograph showing hypercementosis in relation to molars.

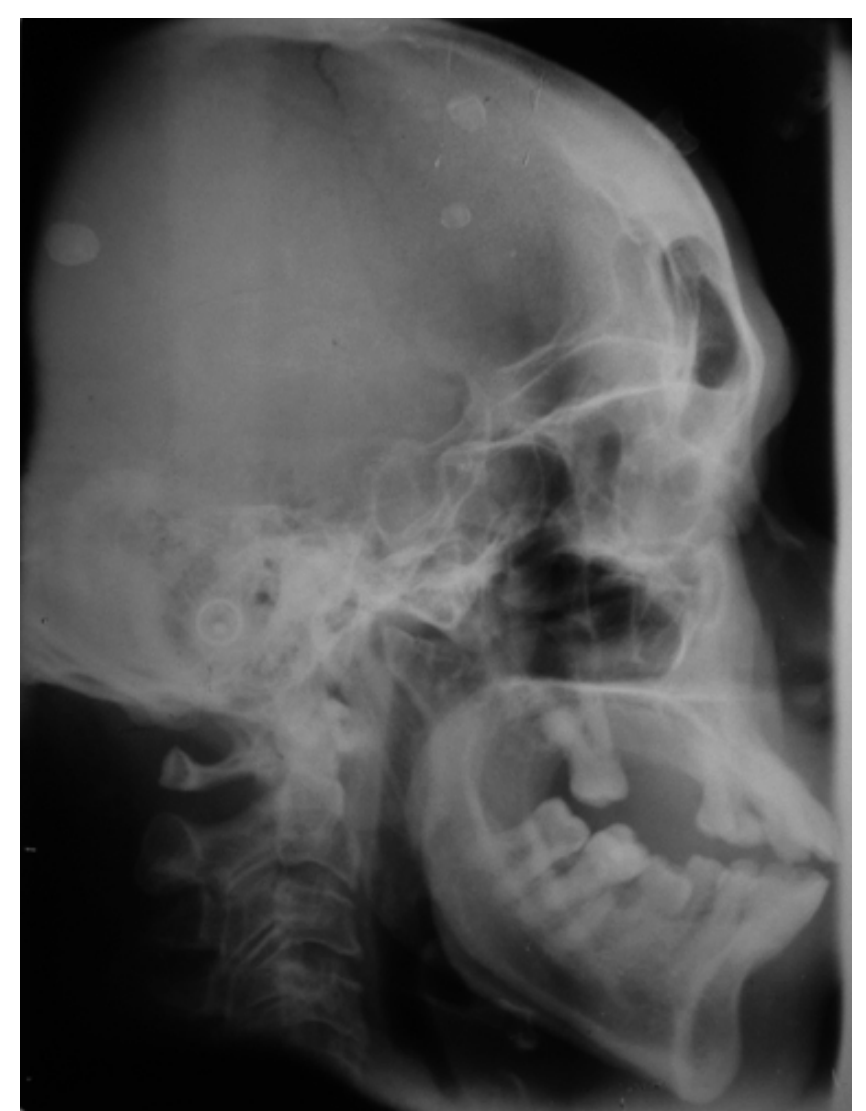

Fig. 5 Lateral cephalogram showing enlarged sella turcica, enlarged frontal sinus, steep mandibular angle and class III profile with prognathic mandible.

response to both growth hormone and IGF-I, periosteal new bone formation leads to an increase in skeletal growth, especially at the level of the mandible. The facial features

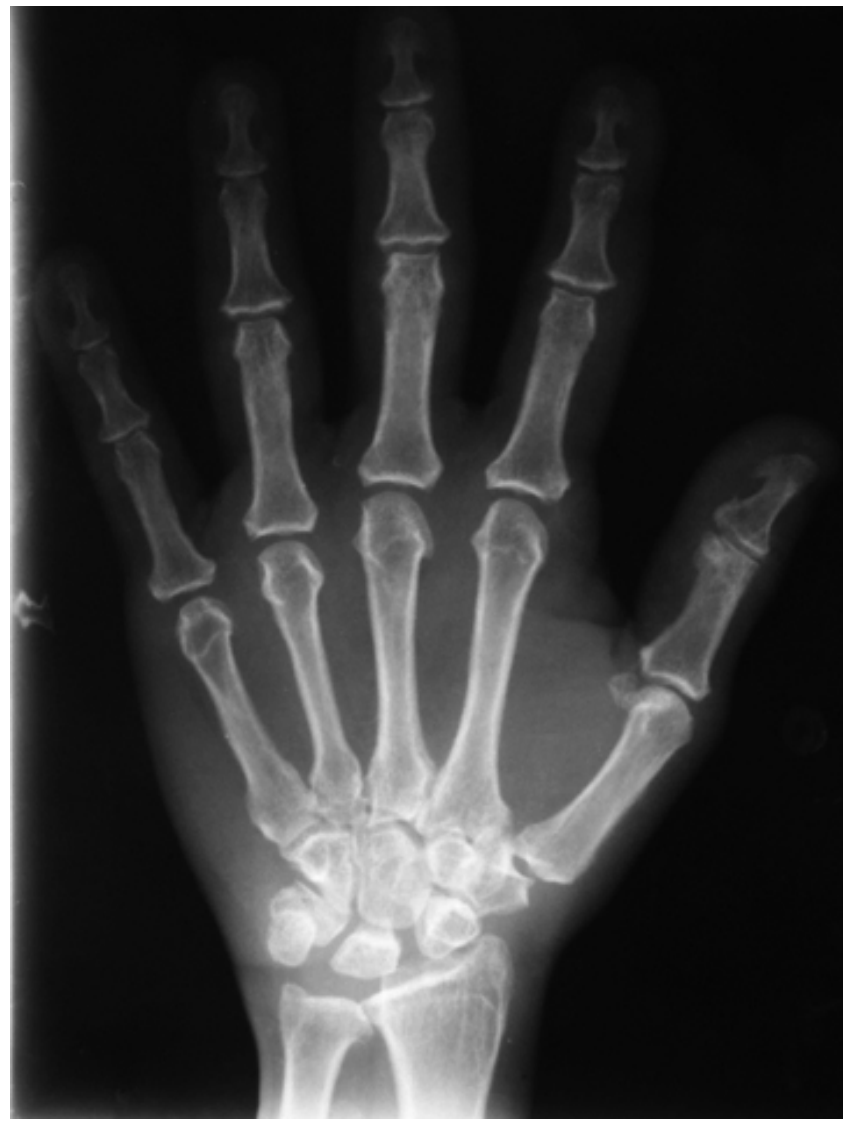

Fig. 6 Hand wrist radiograph showing osteophytes and mineralization of ligamentous insertion.

are characteristic, and patients with acromegaly generally look alike in this respect: the nose is widened and thickened, malar bone becomes prominent, the lips are thick and the facial lines are marked. The forehead and overlying skin becomes thickened, sometimes leading to frontal bossing. There is a tendency towards mandibular overgrowth with prognathism, jaw thickening, maxillary widening, teeth separation and jaw malocclusion. Cortical bone thickens and its porosity diminishes. Hypertrophy of the sinuses, along with laryngeal hypertrophy, explains why the voice tends to become deeper in acromegaly and has a sonorous resonance. Bony deformation also affects the spine, with upper dorsal kyphosis and compensatory lumbar hyperlordosis (1).

Skull radiographs characteristically reveal enlarged sella turcica and enlargement of the paranasal sinuses (especially the frontal sinus). The angle between the ramus and body of the mandible may increase. This, in combination with enlargement of the tongue may result in anterior flaring of the teeth and the development of an anterior open bite. In acromegaly, the most profound growth occurs in the condyle and ramus, often resulting in a class III skeletal 
relationship between the jaws. The thickness and height of the alveolar processes may also increase. The tooth crowns are usually normal in size although the roots of posterior teeth often enlarge as a result of hypercementosis. This hypercementosis may be the result of functional and structural demands on teeth instead of a secondary hormonal effect. Supraeruption of the posterior teeth may occur in an attempt to compensate for the growth of the mandible (5).

Complications most commonly manifested include cardiovascular complications like concentric biventricular hypertrophy or heart failure, respiratory complications like sleep apnoea, which can be suspected based on the presence of snoring, fragmented sleep, daytime somnolence, morning sleepiness and morning headache. Metabolic complications include impaired glucose tolerance, due to growth hormone induced insulin resistance and lipid abnormalities like hypertriglyceridaemia, due to growth hormone dependent inhibition of lipoprotein lipase activity. Acromegalic patients are at increased risk for developing colon adenomas after the age of 50 years. Joint and bone complications include acromegalic arthropathy affecting both axial and peripheral sites. The knee is the most frequently involved joint, followed by shoulder, hip, ankle, elbow and joints of the hand. Endocrine complications include benign thyroid overgrowth, hypogonadism and gonadal dysfunction (6).

The primary aim of therapy directed at patients with acromegaly is to aggressively lower the growth hormone level to $<2.5 \mu \mathrm{g} / \mathrm{l}$. Therapeutic interventions include surgery, radiotherapy, and medical therapy. Radiotherapy is efficacious in controlling tumour growth and growth hormone secretion; however, achievement of biochemical targets may take up to a decade and a number of safety issues have been raised with this treatment modality $(3,7)$. More recently, medical therapy has been increasingly used as primary treatment in selected patients unsuitable for surgery. Clinically available medical therapies for management of acromegaly include dopaminergic agonists, somatostatin analogues, and growth hormone receptor antagonists (3). Surgical therapy includes transsphenoidal approach and transnasal endoscopic approach frontotemporal craniotomy (8).

Successful management of pituitary adenomas may result in reversal of soft tissue abnormalities. However, bony changes may persist and require corrective orthognathic surgery. Orthodontic and maxillofacial surgeons dealing with corrective orthognathic surgery should be well aware of the complications of this disease. Acromegalic patients may report to the dentist with the complaints of malocclusion, difficulty in speech due to enlarged tongue, mobility of teeth or missing teeth secondary to diabetes mellitus. But prosthetic treatment of the patient with acromegaly often requires close cooperation between the various medical and dental specialties. Unusual problems can be expected because of the large mandible, relatively small maxilla, hypertrophic tongue and increased vertical dimension. Post-insertion care of such a patient requires additional time and effort to enhance the acceptance of the new dentures (9). Dental management may be complicated by blindness, diabetes mellitus, hypertension, cardiomyopathic dysarrhythmias or hypopituitarism (10). Thus, invasive or surgical procedures should be carried out only after proper medical evaluation.

\section{References}

1. Chanson P, Salenave S (2008) Acromegaly. Orphanet J Rare Dis 3, 1-17.

2. Holdaway IM, Rajasoorya C (1999) Epidemiology of acromegaly. Pituitary 2, 29-41.

3. Kumar SS, Ayuk J, Murray RD (2009) Current therapy and drug pipeline for the treatment of patients with acromegaly. Adv Ther 26, 383-403.

4. Cordero RA, Barkan AL (2008) Current diagnosis of acromegaly. Rev Endocr Metab Disord 9, 13-19.

5. White SC, Pharaoh MJ (2009) Oral radiology: principles and interpretation. 6th ed, Elsevier, St Louis, 458-460.

6. Scacchi M, Cavagnini F (2006) Acromegaly. Pituitary 9, 297-303.

7. Shih HA, Loeffler JS (2008) Radiation therapy in acromegaly. Rev Endocr Metab Disord 9, 59-65.

8. Laws ER (2008) Surgery for acromegaly: evolution of the techniques and outcomes. Rev Endocr Metab Disord 9, 67-70.

9. Duymuş ZY, Karaalioğlu OF (2009) Prosthetic restoration of a patient with acromegaly - a case report. Atatürk Üniv Diş Hek Fak Derg 19, 41-46.

10. Scully C, Cawson RA (2005) Medical problems in dentistry. 5th ed, Elsevier, St Louis, 95-96. 